\title{
Rates of creatinine clearance in babies less than one week of age
}

\author{
HUUSEYIN SERTEL and JON SCOPES \\ From the Neonatal Research Unit, Institute of Child Health (London University), Hammersmith Hospital, London
}

\begin{abstract}
Sertel, H., and Scopes, J. (1973). Archives of Disease in Childhood, 48, 717. Rates of creatinine clearance in babies less than one week of age. Rates of creatinine clearance were measured in normal newborn babies by collecting a timed specimen of voided urine and estimating plasma creatinine. Each of the 17 babies had the estimation on day 1 and on day 6 of life. The mean rate on day 1 was $17 \cdot 8$ $\mathrm{ml} /$ minute per $1.73 \mathrm{~m}^{2}$, and there was a significant and systematic increase by day 6 when the mean rate was $36.4 \mathrm{ml} /$ minute per $1.73 \mathrm{~m}^{2}$. The findings are important when assessing fluid requirements and drug dosage in the newborn.
\end{abstract}

Although there are a few published individual measurements of creatinine clearance in babies less than a week old (Winberg, 1959, 3 cases; Dean and McCance, 1947, 8 cases with meningomyelocele), we have been unable to find any large series or any systematic examination of changes in the first days of life. Creatinine clearance is a not unreasonable measurement of glomeruler filtration rate in babies (Barnett and Vesterdal, 1953), and is therefore clearly an important measurement since it relates to fluid and electrolyte homoeostasis and rates of excretion of drugs. This paper reports plasma and urine creatinine concentrations and rates of creatinine clearance in 17 normal newborn babies, firstly on day 1 after birth and then again on day 6 .

\section{Methods}

There were 17 babies investigated whose mothers had given permission for the study, 9 girls and 8 boys. Their gestational ages varied from 38 weeks to 41 weeks; birthweights from 2.600 to $4.260 \mathrm{~kg}$, and all were clinically well. All were bottle fed using a cow's milk formula.

The procedure was as follows. The baby was watched until he was seen to pass urine; this specimen was discarded. At this time a stop-watch was started and a urine collecting bag applied. All urine passed was then collected until an occasion when the baby was seen to void again. When this occurred the stop-watch was stopped, the urine bag was removed for measurement of volume of urine and for analysis, and a heel prick specimen of blood was obtained. If any urine was seen to leak, the urine collection was restarted and the baby

Received 29 January 1973. only subjected to a heel prick if a satisfactory collection was obtained.

Thus a timed collection of urine and a sample of blood was obtained. Times of collection ranged from $\mathbf{4 0}$ minutes to 6 hours. Urine creatinine concentration was determined by the alkaline picrate method (Bonsnes and Taussky, 1945). The heel prick blood $(1.0 \mathrm{ml})$ was collected in a tube containing dry heparin, was centrifuged and analysed at once, or was frozen for analysis the next day. The method used was the resin absorption micromethod described by Stoten (1968). Standards and blanks were run with each batch. Confirmatory tests showed that storing frozen plasma did not affect the determination. All analyses were done in duplicate. Surface area was calculated from weight using the formula quoted in Vaughan (1969).

\section{Results}

Fig. 1 shows plasma creatinine concentrations on day 1 and day 6 . There is a systematic and highly significant fall between day 1 and day 6 .

Fig. 2 shows urinary creatinine concentration. Though the mean concentration is higher on day 1 , there were 5 babies in which the urinary concentration rose. Urinary flow rate (Fig. 3) increased from day 1 to day 6 .

Fig. 4 shows creatinine clearance rates expressed as $\mathrm{ml} / \mathrm{min}$ per $1.73 \mathrm{~m}^{2}$. There is a systematic and highly significant increase on day 6 compared with day 1 , though there are three exceptions. The absolute rates of creatinine clearance are very low, by adult standards, both on day 1 and day 6 .

\section{Discussion}

The accuracy of the data on creatinine clearance 

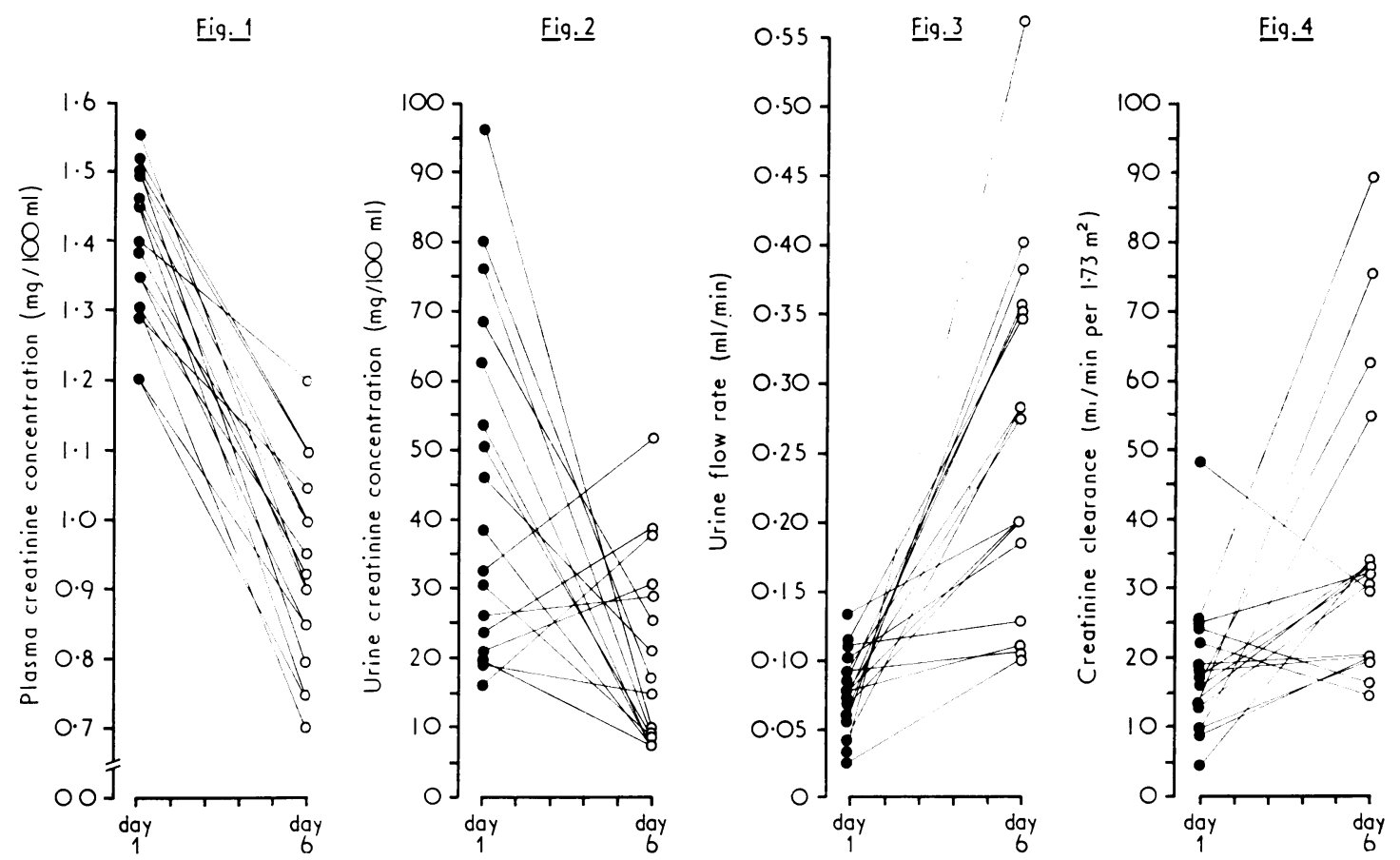

FIG. 1.-Plasma creatinine concentrations on day $1(\bullet)$ and on day $6(O)$. Each pair of tied observations represents an individual baby.

FIG. 2.-Urinary creatinine concentrations.

Fig. 3.-Urinary flow rates.

Fig. 4.-Rates of creatinine clearance.

reported here depends on several factors. By meticulous attention to detail and technique, the accuracy of the measurement of plasma and urine creatinine concentrations, of urine volume, and of timing of sample can be expressed with some confidence. However, it is not possible to exclude inaccuracy occasioned by the baby failing to empty his bladder completely either before or at the end of the collection. It is for this reason that it is usual to collect over a much longer period; in this study simplicity of technique and minimal interference with the baby were thought to outweigh the disadvantages, but the possible inaccuracy must be borne in mind in interpreting the data. The clearance rates are similar to the few reported by Winberg (1959) and to the inulin clearance rates of $\mathrm{Oh}, \mathrm{Oh}$, and Lind (1966). They are not very different from those reported by Dean and McCance (1947) who studied abnormal babies with major spinal defects.

When creatinine clearance rates (taken as a measure of glomerular filtration rate) are plotted against urine flow (Fig. 5), one expects to find no significant correlation. When one considers either the day 1 babies or the day 6 babies, there is no significant correlation between these variables. However, if all the data are pooled, the systematic increase in both urine flow and creatinine clearance from day 1 to day 6 leads to finding a significant correlation. Barnett and Vesterdal (1953) reported a significant correlation, a finding which immediately questioned the validity of creatinine clearance as a measure of glomerular filtration rate. It is possible that their finding resulted from the pooling of data on babies of different ages.

Because of differences in technique, the plasma creatinine concentrations found in this study are not directly comparable with many other published reports. For instance, Josephson, Fürst, and Jārnmark (1962) measured 'apparent serum creatinine' by means of a Jaffé reaction, and Winberg (1959) measured plasma creatinine after absorption with Fuller's Earth. These workers found, in general, lower concentrations than those reported 


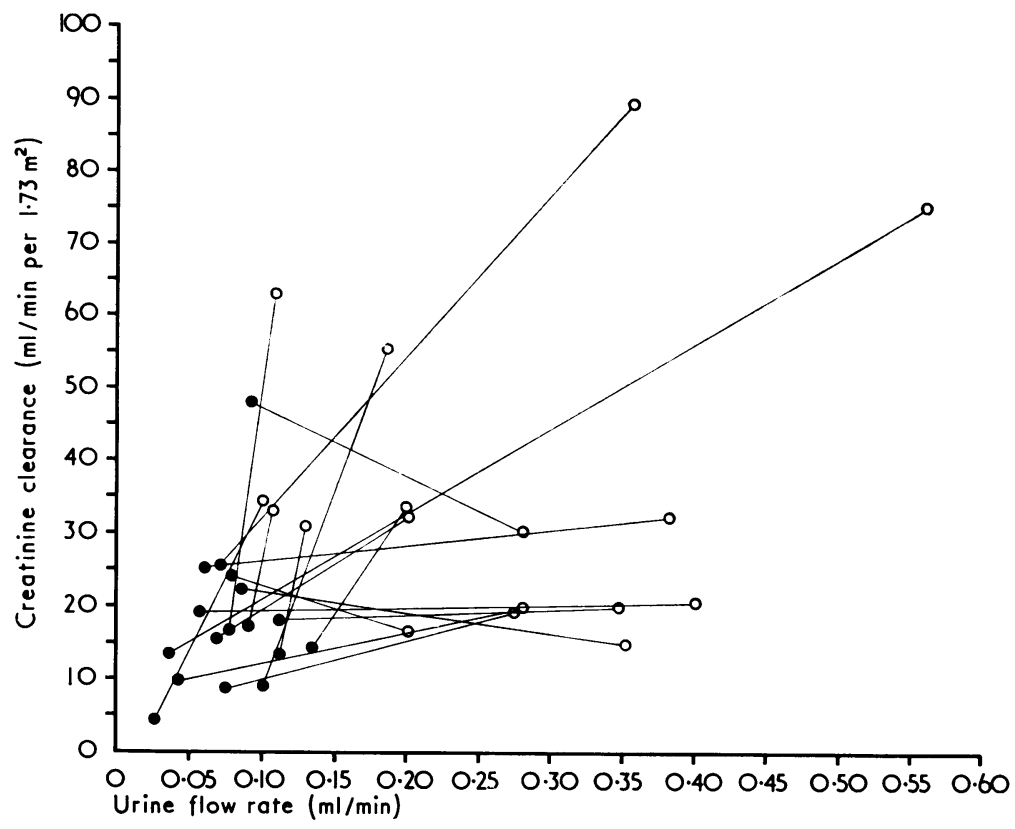

Fig. 5.-Rates of creatinine clearance plotted against urine flow rate. For day 1 babies $(0)$ there is no significant correlation between the variables (correlation coef. $=0 \cdot 1832$, no. $=17$, not significant). The same is true of babies on day $6(O)$ (correlation coef. $=0.1777$, no. $=17$, not significant). If all are considered together, $r=0.4634$, no. $=34$, $0.001<P<0.01$.

here. The particular advantages of the resin absorption method used in this study is discussed by Stoten. (1968). Fig. 1 shows plasma creatinine concentrations which are slightly higher on day 1 than those found in umbilical cord blood, where the level presumably reflects maternal level. At the same time, urine flow rates are very low (Fig. 3), supporting the general concept that renal function is severely limited on day 1 . All the urine creatinine concentrations found (Fig. 2) are low by adult standards.

Fig. 4 shows that though there is a material increase in creatinine clearance on day 6 compared with day 1 , all the values are very low compared with adult values. The importance of these findings lies in assessing fluid and electrolyte requirements and drug therapy in the newborn. The newborn cannot be expected to clear excessive loads of water nor to excrete rapidly those drugs that are eliminated by the kidney. At the same time there has been an appreciable change in creatinine clearance by day 6 , so that one expects, for example, that a drug dosage appropriate on day 1 would need modification by day 6.

\section{Conclusion}

Measurement of creatinine clearance rates by this simple technique involves the baby in minimal interference and gives a quantitative assessment of glomerular filtration rate that is similar to reported inulin clearance studies. The results have clinical importance in assessing fluid and drug requirements not only for groups of babies, but also for controlling the treatment of individual babies.

We are grateful to the University of Istanbul for the support of Dr. Sertel during the study; to the trustees of the Sir William Coxen Trust Fund for provision of laboratory facilities; and to Drs. Elizabeth Hughes and Martin Barratt for help and advice.

\section{REFERENCES}

Barnett, H. L., and Vesterdal, J. (1953). The physiologic and clinical significance of immaturity of kidney function in young infants. Fournal of Pediatrics, $42,99$.

Bonsnes, R. W., and Taussky, H. H. (1945). On the colorimetric determination of creatinine by the Jaffe reaction. Fournal of Biological Chemistry, 158, 581 .

Dean, R. F. A., and McCance, R. A. (1947). Inulin, diodone, creatinine and urea clearances in newborn infants. Fournal of Physiology, 106, 431. 
Josephson, B., Fürst, P., and Järnmark, O. (1962). Age variations in the concentration of non-protein nitrogen, creatinine and urea in blood of infants and children. Acta Paediatrica, Suppl. 135, 111.

Oh, W., Oh, M. A., and Lind, J. (1966). Renal function and blood volume in newborn infant related to placental transfusion. Acta Paediatrica Scandinavica, 55, 197.

Stoten, A. (1968). A micromethod for creatinine using resin to remove interfering substances. Fournal of Medical Laboratory Technology, 25, 240.
Vaughan, V. C., III (1969). Growth and development. In Textbook of Pediatrics, 9th ed., p. 15. Bd. by W. B. Nelson, V. C. Vaughan, and R. J. Mckay. Saunders, Philadelphia.

Winberg, J. (1959). The 24 hour true endogenous creatinine clearance in infants and children without renal disease. Acto Paediatrica, 48, 443.

Correspondence to Dr. J. W. Scopes, St. Thomas's Hospital, London S.E.1.

The following articles will appear in future issues of this journal:

Effects of measles on immune response of Nigerian children. H. C. Whittle, A. Bradley-Moore, A. Fleming, and B. M. Greenwood.

Papular acrodermatitis of childhood: an Australia antigen disease. $F$. Gianotti.

Chronic generalized spinal muscular atrophy of infancy and childhood: arrested Werdnig-Hoffmann disease. $J . H$. Pearn and J. Wilson.

Normal size of liver in infancy and childhood: $x$-ray study. D. Deligeorgis, D. Yannakos, and S. Doxiadis. Quantitative growth and development of human brain. J. Dobbing and J. Sands.

Wiskott-Aldrich syndrome associated with idiopathic infantile cortical hyperostosis (Caffey's disease). G. McEnery and F.W. Nash.

Hereditary pseudo vitamin D deficiency rickets in a Pakistani infant. J. R. Sibert and W. M. U. Moffat. 